(6) Cooperation with Member States in the development of national programmes/actions for the prevention and control of HIV.

National level:-A plan of action for AIDS control is needed for all countries. When once the national HIV epidemiological situation has been assessed, the four major components of the national prevention and control programme can be implemented. These four basic programme components include:

(1) a surveillance system;

(2) laboratory and support capability;

(3) education/information for health-care workers; and

(4) prevention efforts directed to the general public and to specific risk-groups in the population.

The Control Programme on AIDS at WHO Headquarters has been endorsed by the governing bodies (Regional Committees, Executive Board, and the World Health Assembly), and the necessary resources are now becoming available to assist Member States in the design and implementation of their national AIDS control programmes.

\section{Challenge to Society}

HIV infection has created a serious challenge to medical and public-health practice and even to the fabric of society. If we follow the logic of our epidemiological knowledge, HIV prevention will require long-term changes in sexual behaviour, important modifications in blood services and certain medical and paramedical practices, and aggressive approaches to control of perinatal transmission. We cannot imagine a more difficult, serious, or complex, set of challenges. Yet we can afford complacency even less, or pessimistic resignation regarding the individual and societal capacity to alter behaviour in response to a clearly perceived threat. Let us be as clear and scientific as possible in our analysis of HIV as a global public-health problem. Let us unite our resources, material and intellectual, in the confrontation with this virus and its associated disease states. Let us apply the lessons from our heritage of national and international public-health experience, allied to the creativity and vision which the present situation demands.

AIDS may be, or may become, one of the most serious threats to public health in this century; yet we can all still have something to say about the matter. We are working together on AIDS during one of those rare historical moments - at the beginning, really, of a major new global publichealth challenge. Our responsibility is accordingly heavy, and our opportunity to make a difference similarly great. Through the actions which we take, or fail to accomplish, during the next few years, we will indeed be judged by future generations.

\section{FAKHRY ASSAAD, Director Division of Communicable Diseases} $\&$

Jonathan M. Mann, Responsible Officer Control Programme on AIDS World Health Organization

1211 Geneva 27

Geneva, Switzerland.

\title{
Cataclysmic and Global Changes
}

At its latest (21st) General Assembly, held in Bern, Switzerland, the International Council of Scientific Unions (ICSU) organized two symposia to look at the Environmental Consequences of Nuclear War and at the changes that are taking place in, on, and around, our Globe.

\section{Environmental Consequences of Nuclear War}

A major study on the Environmental Consequences of Nuclear War was completed in 1986 by ICSU's Scientific Committee on Problems of the Environment (SCOPE). This scientific, independent examination of the consequences of nuclear war came to the following general conclusions:

1. Multiple nuclear detonations would result in considerable direct physical effects from blast, thermal radiation, and local fallout. The last would be particularly important if substantial numbers of surface bursts were to occur, as the lethal levels of radiation from local fallout would extend for hundreds of kilometres downwind of detonations.

2. There is substantial reason to believe that a nuclear war could lead to large-scale climatic perturbations involving drastic reductions in light-levels and temperatures over large regions within days, and to changes in precipitation patterns for periods of days, weeks, months, or longer. Episodes of short-term, sharply-depressed temperatures could also produce serious impacts - particularly if they occur during critical periods within the growing-season. There is no excuse for asserting with any confidence that there would be no effects of this character and, despite uncertainties in our understanding, it would be a grave error to ignore these potential environmental effects. Any consideration of a postnuclear-war world would have to consider the conse- quences of the totality of physical effects. The biological effects then follow.

3. The systems that currently support the vast majority of humans on Earth (specifically, agricultural production and distribution systems) are exceedingly vulnerable to the types of perturbations that are inevitably associated with climatic effects and societal disruptions. Should those systems be disrupted on a regional or global scale, large numbers of human fatalities associated with insufficient food-supplies would be inevitable. Damage to the food distribution and agricultural infrastructure alone (i.e. without any climatic perturbations) would put a large portion of the Earth's human population in jeopardy of a drastic reduction in food availability.

4. Other indirect effects from nuclear war could-individually and in combination-be extremely serious. These include disruptions of communications, of power distribution, and of societal systems, on an unprecedented scale. In addition, potential physical effects include reduction in stratospheric ozone, and, after any atmospheric smoke had cleared, associated enhancement of ultraviolet radiation, significant global-scale radioactive fallout, and localized areas of toxic levels of air and water pollution.

5. Therefore, indirect effects on human or other biotic populations of a large-scale nuclear war-particularly the climatic effects caused by smoke - could be potentially more consequential globally than the direct effects, while the risks of unprecedented consequences are great for combatant and noncombatant countries alike.

The Committee responsible for the study concluded that: 'Because of the possibility of a tragedy of an unprecedented dimension, any disposition to minimize or ignore the widespread environmental effects of a nuclear war 
would be a fundamental disservice to the future of global civilization."*

Since the SCOPE study was published, a number of workshops and further studies have taken place that put forward ideas for 'nuclear autumns' or 'nuclear springs' to denote smaller reductions in the light and temperature levels. None of these negate the conclusions of the SCOPE study concerning the fact that a large portion of the Earth's human population would be put in jeopardy by a drastic reduction in food availability. Little mention is made in these new studies of the overall effect on the global environment as a whole. The SCOPE study indicates that: whatever the uncertainties, there can be no doubt that a major nuclear war could gravely disrupt the global environment and world society.*

The effects of non-cataclysmic change on our environment was the subject of the other ICSU Symposium.

\section{Global Change}

Although some of us are well aware of the changes which are taking place in our daily-encountered environment, there are few who are conscious of the changes that are taking place in the global environment. We frequently hear about the human destruction of the tropical rain forests and of the primitive tribes living therein, and about the encroachment of deserts, but to most of us these Man-made or Man-induced changes are less evident and appear to be of less concern, than degradation of our local environment.

The publication of Rachel Carson's Silent Spring is said to have been one of the key stimuli that led to a heightened consciousness of some of the changes which were taking place in 1962, and are still going on. But, long before then, not only were people groaning that things were not what they used to be, but there had been a number of international programmes that studied some of the modifications, both natural and anthropogenic, which were taking place in our physical environment. The International Council of Scientific Unions (ICSU) had organized some of these: for example, in 1957-58 the International Geophysical Year (IGY) involved a study of the physical environment, during which the first artificial Earth satellites were launched, followed in 1962 by the International Biological Programme, which was dubbed 'the biologists' International Geophysical Year.' But ICSU had never considered studying in a single programme the changes of our biological, chemical, and physical, environment on the global scale until a proposal was put forward in 1983 to make such a study. The proposal was stimulated by a remark made by the Canadian geophysicist George Garland, who in an ICSU Lecture in 1982 said:

'Today we have a reasonably complete understanding of the links between physical processes affecting our planet and the region around it. Many of the mysteries which remain involve the interaction between these physical processes and biological material, including man himself. Indeed, further progress in some of these areas requires the expertise of literally every discipline now represented in ICSU... This will not only present a challenge to all of the disciplines now represented in ICSU but will require increasing contact with organizations involved with the human and social sciences.'

* and likewise, we would submit, all Nature-see the review of the SCOPE volumes on Environmental Consequences of Nuclear War and Planet in Jeopardy, by Professor Arthur H. Westing, published in Environmental Conservation, 13(3), pp. 281-2, Autumn 1986.-Ed.
In September 1984 a Symposium on Global Change was held in Ottawa, Canada (cf. Environmental Conservation, Vol. 11, No 4, p. 324, Winter 1984) at the ICSU 20th General Assembly and a feasibility study was initiated by a group under the Chairmanship first of Sir John Kendrew and later of Professor Bert Bolin. The report of this group, 'The International Geosphere-Biosphere Programme: A Study of Global Change', was submitted to the ICSU General Assembly in Berne, Switzerland, in September 1986, together with the reports of the four working-groups on (1) Terrestrial Ecosystems and Atmospheric Interactions, (2) Marine Ecosystems and Atmospheric Interactions, (3) Geological Processes: Past and Present, and (4) Upper Atmosphere and Near-space Environment, as well as the report from the COSPAR Working Group on Remote Sensing.

After those presentations and discussions of the study of global change in a special symposium, the ICSU General Assembly decided to launch an International GeosphereBiosphere Programme (IGBP) to describe and understand the interactive biological, chemical, and physical, processes that regulate the total Earth's system -involving atmosphere, Biosphere, hydrosphere, lithosphere, etc.together with the changes that are occurring in this system, and the manner in which they are influenced by human actions. Although concerned with the effects of human actions, the programme so far does not include studies of humans as such, though discussions have taken place with representatives of the International Social Science Council concerning the role of social sciences in such an IGBP.

Priority will be given to the key interactions and significant changes on time-scales of decades to centuries. However, the studies of the history of the Earth's climate which are under way, using a variety of methods - trees' growthrings for short periods, sediments in lakes and in the sea for intermediate periods, and ice-cores for long periods of time-will be used in order to establish what has happened to our environment in the recent past and to analyse better than formerly its present state. Both current and historical data will be used in the development and improvement of global models to test the relative importance of different processes in relation to the dynamics of the global system as a whole. It is expected that by close interaction with the modellers especially of global atmospheric and oceanic circulation and Biosphere trends, we shall be able to improve our practical ability to predict changes that may occur. Such predictions will give decision-makers information which they need to make changes in policies, such as the kinds of energy mixes that produce the smallest amounts of the least noxious wastes and the minimum impact on Man's and Nature's environment.

To be able to improve our understanding and extend our analyses of the environment and of any modifications thereto, we must be able to include the complex web of biological and chemical processes, as well as their interactions with each other and with the physical processes. The climatologists have for some years been dealing with the physics of the atmosphere, the oceans, and the hydrological cycles; but in order to obtain a more detailed understanding than hitherto of the Geosphere-Biosphere interactions, we need to add to the physical models the biogeochemical cycles in the marine and terrestrial environments and the dynamics and chemistry of the atmosphere. The IGBP will endeavour to introduce the modulations resulting from the biological and chemical processes involved, and allow for the relative importance of the time-scales on which they occur.

The Special Committee on Geosphere-Biosphere (SCGB) which was recently established under the Conve- 
norship of Dr John F. McCarthy, will hold its first meeting in 1987 , to be followed by meetings of a number of scientific working-groups to develop the specific programme shortly thereafter.

It is still too early to indicate the types of studies that will be undertaken but, to give an example, one of the proposals which appears likely to be chosen is that for a global-scale study of the ocean's euphotic zone. This was suggested by one of the above-mentioned four working-groups and has the long-term goal of predicting the potential impact of increasing tropospheric concentrations of radiatively active trace-gases on biogeochemical processes in the ocean that are influenced by, and feed back to, climate. It would include air-sea exchange processes, studies of estuarine and coastal zones, and also a wide range of transdisciplinary studies of marine ecosystems - including the problem of storage of fixed carbon in sea-water and sediments. The working group involved suggested that we need to improve our knowledge of the production and consumption of biogenic materials in the upper ocean, and how these will affect the global exchange of $\mathrm{CO}_{2}$ between the atmosphere and the oceans.

The suggestion for such a study of global change has generated great interest among scientists in many disciplines, who have come to realize more and more that the Geosphere and Biosphere are linked together by subtle, complex, and sometimes synergistic, processes - processes that need studying with a variety of techniques and methods, and that may need study over comparatively long periods of time before we shall be able to understand them fully. For example, we are now perceiving signals which indicate that Man is perturbing the natural environment. One of these is the atmospheric warming of about $0.5^{\circ} \mathrm{C}$ that has occurred, over the past 100 years, more steadily in the global record than in Northern Hemisphere land temperatures alone. We can exploit scientifically such perturbations to understand better than formerly, and to analyse, the sensitivities of the environment to natural and human influences.*

\section{Other ICSU Activities}

Toxic Waste Disposal:-The Berne General Assembly noted the conclusions of the report of the Special Committee on Toxic Waste Disposalt and the research needs outlined therein, and asked the ICSU Executive Board to consider the establishment of a working party, perhaps in conjunction with SCOPE, to look into practical ways in which ICSU bodies can contribute to the welfare of Mankind in respect of this most vitally important and pressing problem.**

Biotechnology:-The General Assembly created a Scientific Committee on Biotechnology, the first meeting of which is to be held in 1987 in Amsterdam, Netherlands. One of the studies which this Committee can be expected to undertake in close cooperation with other ICSU committees and with other international bodies, relates to the possible effects on the environment of the deliberate release of genetically altered organisms.

\section{F.W.G. BAKER, Executive Secretary International Council of Scientific Unions 51 Boulevard de Montmorency 75016 Paris, France.}

* Further information about the International Geosphere-Biosphere Programme may be obtained from Professor Thomas Rosswall, Executive Director of IGBP, Royal Swedish Academy of Sciences, Box 50005, S-10405 Stockholm, Sweden.-Ed.

$\dagger$ Available from the present Author.

** Including we would hope that of the concomitant disruption of Nature. - Ed.

\section{Television Trust for the Environment}

The first film to break the news of the famine in Ethiopia, establishment of an independent film-making unit in Brazil, major co-productions with the $\mathrm{BBC}$ on whaling and soil erosion, a European co-production on acid rain, publication of a critical film guide and of educational packs, and the first steps in the establishment of an information network for schools, are among the achievements outlined by the Television Trust for the Environment (TVE) in a report which has recently been published. The Report covers the progress of the editorially independent Trust in its first two years (April 1984-1986). In that period the UNEP- and Central TV-sponsored Trust mobilized close to $\$ 2$ millions for programmes and related projects on environment and development issues.

\section{Ethiopian Series}

TVE made its biggest impact with 'Seeds of Despair', the CENTRAL production which started the famine relief appeal three months before the $\mathrm{BBC} /$ Visnews news report made the big international breakthrough. It was broadcast in the United States by PBS as 'Cry Ethiopia Cry', later going on to win EMMY and Peabody Awards.

'Seeds of Despair' was the first instalment in a series on Ethiopia examining the underlying causes of famine in that unfortunate country. Filmed over two years under the direction of Charles Stewart, the follow-up programme 'Seeds of Hope', showed how exhaustion of the land pushed a village community into disaster. Viewers experienced for the first time what it is like to be on the receiving end of aid, as they saw a relief project disintegrate over a period of months.

A grant from the International Fund for Agricultural
Development (IFAD) then enabled the film crew to go back to Ethiopia to assess what effect the surge in international relief aid was having. The result was 'After the Harvest', a 30 minutes' documentary distributed by Worldwide TV News, which found that the aid was helping, but that the siutation was still critical. Charles Stewart is now back in Ethiopia, where he is following the fortunes of a family from the village who joined the Government's controversial resettlement programme.

The Ethiopian series exemplifies TVE's long-term approach to film-making, which aims to provide the viewer with an insight into how environmental problems develop-sometimes imperceptibly-over a period of years.

\section{Brazilian Series}

TVE's other main CENTRAL-sponsored project is 'Decade of Destruction', a co-production with Brazil's Federal University of Goiás, which is chronicling the fate of the Brazilian Amazon rain-forest. Recipient of the Geneva International Prize for the best film on a development issue, the first programmes in the series focused on the futility of the Amazon colonization schemes. The Brazilian versions have been shown on all of that country's major networks, where they have played an important role in alerting the public to the wastage of the forest's resources.

The next programme in the Amazonian series will be broadcast in 1987. In the process, CENTRAL and TVE are helping the Federal University of Goiás to establish a highly professional film-unit, capable of making its own films for Brazilian transmission when the current project comes to an end in 1990 . 